\title{
High-Payload Nanosuspension of Centella asiatica Extract for Improved Skin Delivery with No Irritation
}

\author{
Eun A Kim \\ Jun Soo Park \\ Min Seop Kim \\ Min Young Jeong \\ Hyun Jin Park \\ Jun Hyuk Choi \\ Jae Hee Seo \\ Yong Seok Choi \\ Myung Joo Kang \\ College of Pharmacy, Dankook \\ University, Cheonan, Chungnam, 330- \\ 7|4, Korea
}

Correspondence: Myung Joo Kang College of Pharmacy, Dankook University, II 9 Dandae-ro, Dongnam-gu, Cheonan, 330-7। 4 , Korea

Tel $+824|550 \quad| 446$

Fax +82 4I 5507899

Email kangmj@dankook.ac.kr
Background: The titrated extract of Centella asiatica (CA) has received much attention as a cosmeceutical ingredient owing to its anti-wrinkle effect. However, due to the low solubility and high molecular weight of pharmacologically active constituents, including asiatic acid (AA), madecassic acid (MA), and asiaticoside (AS), it is challenging to fabricate high-payload topical preparations of CA with satisfactory skin absorption profiles.

Purpose: This study aimed to design a high-payload topical preparation of CA using nanocrystallization technique and to evaluate its skin absorption profile and local tolerability. Methods: High-payload nanocrystal suspensions (NSs) were prepared using lab-scale beadmilling technology, by adjusting the type and amount of suspending agent, CA content, type of vehicle, and milling speed. CA-loaded NSs were characterized in terms of morphology, particle size, crystallinity, and in vitro dissolution pattern. Skin absorption of CA nanocrystals was evaluated using a vertical Franz diffusion cell mounted with porcine skin. In vivo skin irritation following topical application of high-payload NS was assessed in normal rats. Results: The optimized NS system, composed of $10 \%(\mathrm{w} / \mathrm{v}) \mathrm{CA}, 0.5 \%$ polyvinylpyrrolidone (PVP) K30 as steric stabilizer, and $89.5 \%$ of distilled water, was characterized as follows: spherical or elliptical in shape, $200 \mathrm{~nm}$ in size, with low crystallinity. The in vitro dissolution of AA or MA from NSs was markedly faster compared to raw material, under sink condition. Penetration of AA, MA, and AS in the porcine skin was markedly elevated using the highpayload NS formula, providing 5-, 4-, and 4.5-fold higher accumulation in skin layer, compared to that of the marketed cream formula (CA 1\%, Madeca cream). Moreover, topical application of high-payload NS was tolerable, showing neither erythema nor oedema in normal rats.

Conclusion: The novel NS system is expected to be a virtuous approach for offering a better skin absorption of CA, without using an excess quantity of solubilizers.

Keywords: Centella asiatica, asiatic acid, madecassic acid, asiaticoside, nanocrystal suspension, bead-milling, dissolution, skin absorption, skin irritation

\section{Introduction}

Titrated extract of Centella asiatica (CA), also known by common names of Gotu kola or Tiger Grass, is gaining popularity as a novel cosmeceutical ingredient showing effectiveness in tissue regeneration, ${ }^{1}$ cell migration, ${ }^{2}$ and wound repair, ${ }^{3}$ by promoting fibroblast proliferation and collagen synthesis. ${ }^{4,5}$ The CA extract contains three principal constituents, namely asiaticoside (AS), asiatic acid (AA) and madecassic acid (MA) (Figure 1), along with several phytochemical constituents, such as flavonoids, sesquiterpenes, plant sterols, pentacyclic triterpenoids, or 
A

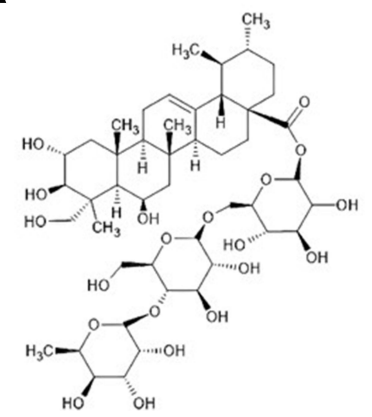

B

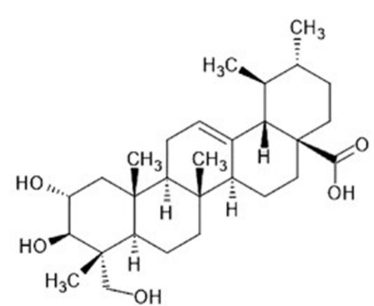

C

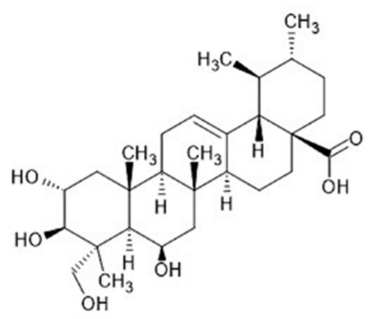

Figure I Chemical structure of (A) AS, (B) AA, and (C) MA.

Abbreviations: AS, asiaticoside; $A A$, asiatic acid; $M A$, madecassic acid.

eugenol derivatives. ${ }^{6}$ Topical application of CA stimulates fibroblast proliferation and activates the Smad signaling pathway, increasing the type I collagen production and decreasing the formation of stretch marks and inflammatory reactions. ${ }^{7,8}$ Moreover, AA and MA increase the microcirculation of blood in the skin and prevent excessive accumulation of fat in cells. ${ }^{9-11}$

To initiate tissue regeneration and wound healing activities of CA, proficient delivery of the bioactive ingredients into the relevant skin layers across the stratum corneum is a prerequisite. The stratum corneum, ie, the uppermost layer of the epidermis with a thickness of $10-15 \mu \mathrm{m}$, represents the greatest challenge for the penetration of active substances into epidermis and dermis. ${ }^{12,13}$ It is composed of 15-20 cell layers of corneocytes that are embedded in a lipid-enriched intercellular space consisted of principally ceramides, free fatty acids, and cholesterol. $^{14,15}$ The high molecular weight (959.1 daltons) and hydrophilicity ( $\log P$ value of 0.1$)$ of AS prevent the penetration of the pentacyclic triterpene across the stratum corneum. Furthermore, solubilization techniques are additionally required to formulate external preparations and to impede penetration of the hydrophobic aglycones into the skin layer. AA and MA are poorly water-soluble lipophilic ingredients with partition coefficient $(\log P)$ values of 5.7 and 4.3 , respectively. ${ }^{16}$

Different pharmaceutical approaches such as employment of penetration enhancers, lipid nanoparticles, micelles, liposomal, and niosomal vesicle systems have been implemented to enhance the solubility of the waterinsoluble ingredients and to promote skin absorption into relevant skin layers. ${ }^{16-19}$ These approaches have been effective in increasing the skin absorption of the active ingredients of CA, with improved pharmacological activities. $^{16,17}$ However, even with these solubilization systems, the content of $\mathrm{CA}$ in external formulations has been restrained below $1.0 \% \mathrm{w} / \mathrm{v}$, because of the low solubility of AA or MA in formulations. Additionally, previous skin absorption-enhancing approaches for CA include high contents of surfactants, fatty acids, or cosolvents as solubility or penetration enhancers, which may cause skin irritation such as itching, rash, and even local inflammation after long-term application. ${ }^{20}$

Recently, drug nanocrystal suspension (NS) has been in the spotlight as a promising topical as well as transdermal delivery system for lipophilic pharmaceuticals and cosmetic substances. ${ }^{21-23}$ Drug nanocrystals are colloidal dispersions of sub-micronized drug particles stabilized using minimal polymeric or amphiphilic stabilizers in a continuous phase. ${ }^{24,25} \mathrm{~A}$ decrease in particle size leads to an increase in surface area, which is favorable for the adhesion of drug particles to biological membranes. ${ }^{26,27}$ Moreover, the increased dissolution rate and saturation solubility intensifies the concentration gradient between the biological membranes including stratum corneum and topical preparation, subsequently allowing higher penetration into skin layers. ${ }^{28-30}$ Moreover, an increase in the particle curvature with a crystal size below $500 \mathrm{~nm}$ facilitates the penetration of intact drug particles into the skin through the hair follicles and its subsequent absorption by the surrounding follicular epithelium. ${ }^{31}$ Particularly, nanosuspension system allows high drug-loading in topical preparation by dispersing the insoluble compound in solid state with minimal use of suspending agent, rather than in dissolved state in continuous phase. ${ }^{32,33}$

Herein, the aim of this study was to design a highpayload NS for CA to facilitate the skin absorption of its three main constituents (AA, MA, and AS). High-payload NSs were prepared using a lab-scale bead-milling technology with various formulation variables, such as the type 
and amount of suspending agent, CA concentration, type of vehicle, and milling speed. The NS of CA was characterized in terms of morphology, particle size, crystallinity, and in vitro dissolution pattern under sink condition. In vitro skin absorption of CA nanocrystals depending on CA content $(1,5$, and $10 \mathrm{w} / \mathrm{v} \%$ ) or type of vehicle (distilled water (DW) or mixture of DW and cosolvent) was evaluated using a vertical Franz diffusion cell mounted with porcine skin. Moreover, in vivo skin irritation following the application of novel high-payload CA system was further assessed in normal rats.

\section{Materials and Methods}

\section{Materials}

Dehydrated titrated extract of CA, containing 36-44\% of AS and $54-66 \%$ of AA or MA, was obtained from Nanning Weikang Pharmaceutical Technology Co. Ltd. Polyvinylpyrrolidone K30 (PVP K30), polyoxyl 35 castor oil, vinylpyrrolidone-vinyl acetate copolymer (Kollidon VA64), polyoxyl 40 hydrogenated castor oil (Kolliphor RH40), and poloxamer 188 were obtained from Basf Co. (Ludwigshafen, Germany). Acrylic acid crosslinked with allyl sucrose or allyl pentaerythritol (Carbopol 934NF), polyoxyl 15 hydroxystearate (Kolliphor HS15), tyloxapol, polyoxyl (PEG) 40 stearate, butylene glycol (BG), polysorbate 20, and polysorbate 80 were supplied from Masung \& Co. Ltd. (Seoul, Korea). Hypromellose (HPMC E50LV) was acquired from Whawon Pharm Co. Ltd. (Seoul, Korea). Analytical standards of AS, AA, and NA, carboxymethyl cellulose sodium (Na. CMC), lecithin, methylcellulose, and phosphate-buffered saline tablet were purchased from Sigma Chemical Co. (St. Louis, MO, USA). HPLC grade acetonitrile and methanol were purchased from J.T. Baker (Phillipsburg, NJ, USA). All other chemicals were of analytical grade and used without further refinement.

\section{Preparation of CA NS by Bead-Milling Technique}

The NSs of CA were fabricated by pulverizing drug powder into fine particles in an aqueous vehicle using lab-scale bead-milling technique. ${ }^{34,35}$ Approximately 5$20 \mathrm{mg}(0.5-2.0 \%, \mathrm{w} / \mathrm{v})$ of the suspending agent listed in Table 1 was added to $1 \mathrm{~mL}$ of aqueous vehicle (DW or mixture of DW and BG $(1: 1 \mathrm{v} / \mathrm{v}))$ and vortexed for 30 min to obtain a clear solution. Next, 10-100 mg of CA and $1 \mathrm{~g}$ of zirconia beads $(3 \mathrm{~mm})$ were added to the solution and pre-wetted for 5 min using a multi-vortex

Table I Effect of Suspending Agent on the Particle Size, and Size Homogeneity of CA-Loaded NSs

\begin{tabular}{|l|c|c|c|c|}
\hline \multirow{2}{*}{ Stabilizers } & \multicolumn{2}{|c|}{ Immediately After Preparation } & \multicolumn{2}{c|}{ After Centrifugation at I3,000 rpm for I0 min } \\
\cline { 2 - 5 } & Particle Size (nm) $^{\mathbf{b}}$ & Homogeneity (PDI) $^{\mathbf{b}, \mathbf{c}}$ & Particle Size (nm) $^{\mathbf{b}}$ & Homogeneity (PDI) $^{\mathbf{b}, \mathbf{c}}$ \\
\hline Polymers & & & & \\
PVP K30 & $201.4 \pm 5.0$ & $0.24 \pm 0.01$ & $219.7 \pm 12.6$ & $0.29 \pm 0.03$ \\
Carbopol 934NF & $177.7 \pm 0.5$ & $0.21 \pm 0.02$ & $234.0 \pm 1.1$ & $0.25 \pm 0.01$ \\
Na. CMC & $347.3 \pm 4.9$ & $0.20 \pm 0.01$ & $361.8 \pm 3.9$ & $0.16 \pm 0.02$ \\
Methylcellulose & $271.3 \pm 3.6$ & $0.29 \pm 0.00$ & $378.2 \pm 4.0$ & $0.32 \pm 0.01$ \\
HPMC E50LV & $144.6 \pm 5.8$ & $0.28 \pm 0.01$ & $318.3 \pm 1.3$ & $0.26 \pm 0.01$ \\
Kollidon VA64 & $224.2 \pm 2.0$ & $0.20 \pm 0.00$ & $255.3 \pm 2.0$ & $0.24 \pm 0.01$ \\
\hline Surfactants & & & & \\
Tyloxapol & $326.1 \pm 5.9$ & $0.35 \pm 0.05$ & $318.2 \pm 3.7$ & $0.36 \pm 0.02$ \\
Kolliphor HSI5 & $217.7 \pm 4.0$ & $0.24 \pm 0.02$ & $215.7 \pm 7.5$ & $0.28 \pm 0.01$ \\
Poloxamer 188 & $321.4 \pm 11.7$ & $0.35 \pm 0.04$ & $548.5 \pm 19.2$ & $0.51 \pm 0.02$ \\
Kolliphor EL & $275.8 \pm 2.8$ & $0.26 \pm 0.04$ & $268.0 \pm 3.6$ & $0.29 \pm 0.03$ \\
Lecithin & $260.5 \pm 4.0$ & $0.33 \pm 0.04$ & $346.2 \pm 2.3$ & $0.31 \pm 0.00$ \\
PEG 40 stearate & $273.7 \pm 1.6$ & $0.26 \pm 0.01$ & $399.3 \pm 2.4$ & $0.43 \pm 0.01$ \\
Polysorbate 20 & $281.3 \pm 1.8$ & $0.29 \pm 0.05$ & $415.3 \pm 5.8$ & $0.41 \pm 0.04$ \\
Polysorbate 80 & $278.5 \pm 2.0$ & $0.29 \pm 0.03$ & $455.3 \pm 28.6$ & $0.49 \pm 0.09$ \\
Kolliphor RH 40 & $308.2 \pm 3.2$ & $0.30 \pm 0.05$ & $430.6 \pm 12.6$ & $0.38 \pm 0.04$ \\
\hline
\end{tabular}

Notes: ${ }^{a}$ The concentration of CA and stabilizer in the NS formulas were set to $100 \mathrm{mg} / \mathrm{mL}$ and $5 \mathrm{mg} / \mathrm{mL}$, respectively, with milling speed of $1500 \mathrm{rpm}$ for 4 h. All samples were uniform after preparation, and even after centrifugation at $13,000 \mathrm{rpm}$ for $10 \mathrm{~min}$; ${ }^{\mathrm{b}}$ Data are expressed as mean $\pm S D$ ( $\mathrm{n}=3$ ); ${ }^{\mathrm{C}} \mathrm{Calculated}$ by dividing weight average molecular weight by number average molecular weight.

Abbreviations: CA, Centella asiatica; NS, nanocrystal suspensions. 
at room temperature. The coarse dispersion was beadmilled using the ZentriMix 380R (Andreas Hettich GmbH und Co KG, Tuttlingen, Germany) at different speeds $(1200,1500$, and $1800 \mathrm{rpm})$ for $4 \mathrm{~h}$. For every milling trial, the cooling device was set to $-10{ }^{\circ} \mathrm{C}$ to prevent thermal degradation of $\mathrm{CA}$ during fabrication process. Prepared NSs were separated from the beads, placed in scintillation vials, and stored under ambient condition for further experiments.

\section{Morphological or Physical}

\section{Characterization of CA-Loaded NSs} Morphological Observation of CA Nanocrystals

Morphological features of raw material and CA nanocrystals dispersed in aqueous vehicle were examined using a scanning electron microscope (SEM, Model JSM-6510, JEOL, Tokyo, Japan). Approximately $20 \mu \mathrm{L}$ of NS was loaded on an aluminum stub by using double-sided tape and desiccated at room temperature for 2 $\mathrm{h}$, to deplete the aqueous vehicle. Next, dried NS or raw material were coated with platinum by using an automatic sputter coater (Model 108AUTO, Cressington, $\mathrm{UK})$ at $20 \mathrm{~mA}$ for $10 \mathrm{~min}$. Micrographs of the coated samples were observed and pictured at an acceleration voltage of $20 \mathrm{kV}$.

\section{Determination of Size Distribution of CA NSs}

The mean particle size and polydispersity index (PDI), the width of size distribution, of CA-loaded NS was analyzed using Zetasizer Nano ${ }^{\circledR}$ Instruments (Malvern Instruments, UK) ${ }^{36,37}$ Samples $(100 \mu \mathrm{L})$ were diluted 10 -fold using DW and then loaded onto disposable cells. The size distribution of NS was analyzed using a $4 \mathrm{~mW}$ He-Ne laser $(633 \mathrm{~nm})$ at $25^{\circ} \mathrm{C}$, with a $90^{\circ}$ scattering angle.

\section{Analysis of X-Ray Powder Diffraction of CA Nanocrystals}

X-ray diffraction patterns of raw material, CA nanocrystals, and vehicle were analyzed using an X-ray diffractometer (XRD, Model Ultima IV, Rigaku, Japan). NS samples were centrifuged at $3500 \times \mathrm{g}$ for $10 \mathrm{~min}$ to isolate drug nanocrystals from the aqueous vehicle. The collected CA nanocrystals were desiccated in the oven at $60{ }^{\circ} \mathrm{C}$. Samples were loaded on the glass plate, and the diffraction pattern over a $2 \theta$ range of $5^{\circ}-30^{\circ}$ was scanned using $\mathrm{Cu}$ $\mathrm{K} \alpha$ radiation generated at $30 \mathrm{~mA}$ and $40 \mathrm{kV}$. Scan speed was set at $1.0 \mathrm{~s} / \mathrm{step}$, with a step size of 0.02 .

\section{Thermal Analysis of CA Nanocrystals}

The thermal behaviors of raw material, solidified nanocrystals, and vehicle were examined using differential scanning calorimeter (DSC, Model DSC 50, Shimadzu, Japan). Nanocrystals were collected using ultracentrifugation and subsequent drying processes, as described in "analysis of X-ray powder diffraction of CA nanocrystals section". Each sample in solid state (approximately $2 \mathrm{mg}$ ) was placed in a standard aluminum pan and sealed with a lid. The phase transition of each sample was recorded at the heating rate of $10{ }^{\circ} \mathrm{C} / \mathrm{min}$, with a nitrogen purge of $20 \mathrm{~mL} / \mathrm{min}$. An empty aluminum pan was used as the reference.

\section{HPLC Analysis of AA, MA, and AS}

Several simultaneous quantification methods using HPLC analysis have been reported for the three $\mathrm{CA}$ components $^{38-40}$; however, analytical problems include low sensitivity or time-consuming gradient process. Accordingly, an HPLC analysis method for AS, a hydrophilic ingredient, and another HPLC analysis method for simultaneous determination of lipophilic compounds (AA and MA) have been established.

The concentration of AS in the sample was analyzed using Shimadzu HPLC composed of a pump (Model 515 pump), a UV-VIS (ultraviolet-visible) detector (Model 486), and an autosampler (Model 717 plus). The mobile phase, comprising DW and acetonitrile at a 7:3 volume ratio, was allowed to flow through the reversed-phase $\mathrm{C} 18$ column $(4.6 \mathrm{~mm} \times 50 \mathrm{~mm}, 5.0 \mu \mathrm{m}$, Fortis $)$ at a flow rate of $1.0 \mathrm{~mL} / \mathrm{min}$. The column temperature was set to $25^{\circ} \mathrm{C}$. A $20 \mu \mathrm{L}$ of aliquot was injected, and the column eluent was monitored at a wavelength of $210 \mathrm{~nm}$. The concentration of the lipophilic compounds including MA and AA was determined using Waters HPLC system composed of a pump (Model 515 pump), a UV-VIS (ultraviolet-visible) detector (Model 486), and an autosampler (Model 717 plus), equipped with the reversed-phase C18 column $(4.6 \mathrm{~mm} \times 50 \mathrm{~mm}, 1.8 \mu \mathrm{m}$, Agilent, Santa Clara, CA, USA). The mobile phase, comprising acetonitrile and DW at a 5:5 volume ratio, was run at a flow rate of $1.2 \mathrm{~mL} / \mathrm{min}$. The column temperature and detection wavelength was set at $25^{\circ} \mathrm{C}$ and $210 \mathrm{~nm}$, respectively. The retention time of AA and MA was approximately 6.0 and $7.1 \mathrm{~min}$, respectively.

The established HPLC method was inter-day validated by the aspect of linearity, accuracy, precision, 
limit of detection (LOD), and limit of quantification (LOQ). For each component (AS, AA, and MA), five different concentrations were prepared by serial dilution of stock solution by using the mobile phase. After analyzing three sets of samples, analytical accuracy for each concentration was calculated using the following equation: calculated concentration/nominal concentration $\times 100$, and analytical precision was calculated using the following equation: standard deviation of calculated concentration/average of calculated concentration $\times$ 100. The LOD and LOQ for the method were calculated based on the standard deviation of the response $(\sigma)$ and slope approach. The LOD was calculated using the formula $3.3 * \sigma /$ slope, and the LOQ was calculated using the formula $10 * \sigma /$ slope.

\section{In vitro Dissolution Profile of AS, AA, and MA from CA-Loaded NSs}

In vitro dissolution profile of $\mathrm{AS}, \mathrm{AA}$, and $\mathrm{MA}$ from CA-loaded NSs or the micronized raw material was comparatively evaluated using the USP 2 paddle method (Model DT 720, Erweka). Each formula containing $10 \mathrm{mg}$ of CA was added to $500 \mathrm{~mL}$ of dissolution medium maintained at $32{ }^{\circ} \mathrm{C}$ and stirred at paddle speed of $100 \mathrm{rpm}$. To provide sink condition with adequate solubility for $\mathrm{AS}, \mathrm{AA}$, and MA, 1\% (w/v) of sodium lauryl sulfate (SLS) was added to $10 \mathrm{mM}$ phosphate buffer. The dissolution media $(1 \mathrm{~mL})$ was withdrawn by syringe and replaced with equal volume of pre-warmed dissolution media at predetermined times $(15,30,45,60,120$, and $240 \mathrm{~min})$. Withdrawn samples were centrifuged at $13,000 \mathrm{rpm}$ for $5 \mathrm{~min}$, removing undissolved materials including the drug nanocrystals. The supernatant $(500 \mu \mathrm{L})$ was then fivefold diluted with methanol and analyzed using HPLC as described earlier.

\section{Skin Permeation and Retention Profiles of CA-Loaded NSs}

In vitro skin permeation or retention of three principal constituents of CA after topical application of NSs was evaluated using a vertical Franz diffusion cell model. ${ }^{41-43}$ One hour before the experiment, frozen porcine skin tissue (thickness: 0.8-1.2 mm, Cronex Co. Ltd Gyeonggi-do, Korea) was thawed at room temperature, the subcutaneous fat and muscle tissues were removed, and the skin tissue was washed using phosphate buffer solution ( $\mathrm{pH} 7.4)$. The diffusion area of the Franz diffusion cell was set to $1.76 \mathrm{~cm}^{2}$. As the receptor medium, $9 \mathrm{~mL}$ of phosphate buffer containing $1 \%(\mathrm{w} / \mathrm{v})$ SLS was employed to guarantee sink condition for the three components. After the temperature of receptor media was equilibrated at $32 \pm$ $0.5^{\circ} \mathrm{C}, 250 \mu \mathrm{L}$ of NSs $(1 \% \mathrm{NS}, 5 \% \mathrm{NS}, 10 \% \mathrm{NS}-1$, and $10 \%$ NS-2) were applied to the skin ( $n=4$ per each group). A commercially available topical product containing $1 \%$ CA (Madeca cream) was used as the control group. At predetermined time intervals $(0,1,2,4,6,8,10,12$, and $24 \mathrm{~h}), 250 \mu \mathrm{L}$ of receptor media was withdrawn and replaced with fresh receptor medium. Each withdrawn sample was centrifuged at 13,000 rpm for $10 \mathrm{~min}$, and supernatant was fivefold diluted with methanol, followed by HPLC analysis.

After $24 \mathrm{~h}$ of in vitro skin permeation study, the amount of AS, AA, or MA accumulated in the skin layer was further determined, according to previous literature. ${ }^{41}$ The skin surface was gently wiped using Kim's wiper to remove CA formulas, which may adhere to and remain on the surface of the skin. The collected skins were then accurately weighed, cut into small pieces, and immersed in $10 \mathrm{~mL}$ of methanol. The drug deposited in the skin was extracted by vigorous stirring at room temperature using a shaking incubator for $24 \mathrm{~h}$. The solution was then centrifuged at 13,000 rpm for $5 \mathrm{~min}$, and the concentration of AS, AA, and MA in the upper layer was analyzed using HPLC.

\section{Skin Irritation Test of High-Payload CA NS}

The skin tolerability of the high-payload CA NSs was assessed in normal rats according to the previous reports. $^{44,45}$ This animal study was conducted after the approval of Institutional Animal Care and Use Committee (IACUC) of Dankook University (Cheonan, Korea) (DKU-19-032, 8 October 2019) following $\mathrm{NIH}$ Guide for the Care and Use of Laboratory Animals (The National Academies Press, 8th Ed., 2011). Sprague Dawley rats (male, 150-200 g, 6-week-old) obtained from Samtako Bio Korea (Gyeonggi-do, Korea) were accommodated under temperature $\left(23 \pm 1^{\circ} \mathrm{C}\right)$ and light cycle (day/night: 12 hours) with free access to feed and water ad libitum. The acclimatized rats were randomly divided into four groups ( $\mathrm{n}=4$ per group), and dorsal skin surfaces were shaved after anesthetization by chloroform inhalation. After removing the hairs on the dorsal area, 
$200 \mu \mathrm{L}$ of each sample (vehicle, $10 \% \mathrm{NS}-1,10 \% \mathrm{NS}-2$, or Madeca cream as positive control) was topically applied and spread evenly over the dorsal skin $\left(6 \mathrm{~cm}^{2}\right)$. Each formula was topically applied every $24 \mathrm{~h}$ for 5 days, and the degree of erythema or oedema was evaluated each day prior to application. The severity of skin irritation was graded as follows: Erythema scoring; No erythema, 0; Very slight erythema, 1; Well-defined erythema, 2; Moderate-to-severe erythema, 3; Severe erythema to eschar formation, 4; Oedema scoring, No oedema, 0; Very slight oedema, 1; Slight oedema, 2; Moderate oedema, 3; Severe oedema, $4 .^{45,46}$

\section{Statistical Analysis}

Raw data were statistically analyzed using one-way analysis of variance (ANOVA), followed by post hoc analysis for multiple comparisons (SPSS software 17, SPSS Inc., Chicago, IL, USA). Statistical significance was set at $\mathrm{p}$ value $<0.05$.

\section{Results and Discussion}

\section{Formulation Development and Selection of Suspending Agent of CA NS}

To improve skin absorption profiles of pentacyclic triterpenes (AS, AA, or MA), principal pharmacologically active compounds of $\mathrm{CA}$, several carrier systems such as liposomes, transfersomes, nanostructured lipid carriers, or niosome have been implemented. ${ }^{16-19}$ These pharmaceutical approaches could improve the penetration into skin layers with increased therapeutic efficacy such as increased dermal thickness in animal models. Nevertheless, the content of $\mathrm{CA}$ in these formulations was restrained, ranging from $0.1 \%$ to $1.0 \%(\mathrm{w} / \mathrm{v})$ due to its low solubility and/or limited loading in the vesicles. Low levels of these pharmacologically active compounds could not provide a sufficient concentration gradient between the skin and the topical preparations, thereby restraining absorption in the skin layer. Therefore, as an alternative, we designed a high-payload topical preparation of CA by using nanocrystallization technology. This alternative approach is expected to promote skin absorption of the pentacyclic triterpenes by providing a high concentration gradient between the topical formulation and biological membrane, leading to an elevated diffusive flux value, with minimal use of potentially harmful solubilizers, including surfactants.
NSs of CA have been fabricated using wet milling technique, a top-down approach, comminuting coarse $\mathrm{CA}$ raw material to sub-micron dimensions in an aqueous vehicle. Mechanical grinding using media milling beads provides the following advantages: low-energy utilization, ease of scale-up, no use of organic solvent, and minimum batch to batch variation, compared to other nanosizing techniques. ${ }^{47-49}$ To design a CA NS, different hydrophilic polymers and surfactants were first screened as suspending agents to prevent drug aggregation or precipitation of $\mathrm{CA}$ particles in the aqueous vehicle. Neutral, hydrophilic polymers included in the dispersion system might be adsorbed onto the particle surface and consequently inhibit crystal growth via steric hindrance. ${ }^{48}$ Nonionic surfactants lower the surface free energy of the dispersion system by decreasing the interfacial tension between hydrophobic drug particle and aqueous medium. ${ }^{50}$ While screening the suspending agent, the concentrations of $\mathrm{CA}$ and suspending agent in the vehicle were fixed at $100 \mathrm{mg} /$ $\mathrm{mL}$ and $5 \mathrm{mg} / \mathrm{mL}$, respectively, with stirring speed set at 1800 rpm. As shown in Table 1, all CA-loaded NSs prepared using hydrophilic polymers or surfactants were uniform in size, immediately after preparation. The mean particle size of CA particles was 144-347 $\mathrm{nm}$, and PDI value, an indicator of size uniformity, was less than 0.35. Particularly, smaller CA particles were obtained using PVP K30 (201.4 nm), carbopol 934NF (177.7 nm), HPMC E50LV (144.6 nm), or Kolliphor HS15 (217.7 nm).

Subsequently, the physical stability of the CA-loaded nanosuspensions, depending on the type of suspending agent, was comparatively evaluated under stress condition, accelerating aggregation or precipitation of drug particles, by centrifugation at 13,000 rpm. After centrifugation, samples were re-suspended using multi-vortex for $1 \mathrm{~min}$, and the homogeneity and the particle size were evaluated. Under stress condition, the uniformity of the nanosuspension was upheld, but the crystal size increased. The particle size of NSs prepared using poloxamer 188 , polysorbate 20 , polysorbate 80 , or polyoxyl 40 hydrogenated castor oil increased over $400 \mathrm{~nm}$ (Table 1). Conversely, when PVP K30 or Kolliphor HS15 was included as a dispersant in the vehicle, the NSs were physically stable, exhibiting a particle size of 219.7 and $215.7 \mathrm{~nm}$, respectively, even after centrifugation. PVP polymer, a hydrogen-bond acceptor polymer, might be adsorbed on the surface of CA nanocrystals via 
hydrogen bonding and/or van der Waals interaction, predominantly contributing to the dispersion of hydrophobic nanocrystals in the aqueous media with no aggregation. In the case of Kolliphor HS15, the hydrophobic portion of amphiphilic stabilizer might adsorb onto the drug crystal surface, effectively decreasing the interfacial tension and surface free energy between the drug particle and aqueous vehicle. Among them, PVP $\mathrm{K} 30$, a linear polymer of 1-vinyl-2-pyrrolidone monomers with an established safety in animal models, was selected as a dispersant of CA-loaded NS. In animal studies, no evidence of marked skin irritation or sensitization was observed using PVP solution even at concentrations of $10 \%(\mathrm{w} / \mathrm{v}) .^{51}$

\section{Effect of Process or Formulation Variables on Particle Size of CA Nanosuspensions}

The particle size and uniformity of CA-loaded NS depending on compositional variables (PVP K30 concentration, drug concentration, or vehicle) or process parameters (bead-milling intensity) were assessed. First, the effect of PVP K30 concentration and bead-milling intensity on crystal size was evaluated by adjusting the concentration of the hydrophilic polymer and milling intensity to 5,10 , or $20 \mathrm{mg} / \mathrm{mL}$ and 1200,1500 , or $1800 \mathrm{rpm}$, respectively (Figure 2A). As expected, the particle size of CA nanocrystals tended to decrease with an increase in the strength of mechanical grinding, in all PVP K30 concentrations tested. Uniform nanosuspensions with sizes ranging from 190 to $230 \mathrm{~nm}$ were lucratively fabricated using milling intensities of $1500 \mathrm{rpm}$ or $1800 \mathrm{rpm}$, with no marked difference in the PVP concentration $(5,10$, or $20 \mathrm{mg} /$ $\mathrm{mL}$ ). On the other hand, the particle size increased to $340 \mathrm{~nm}$ at $1200 \mathrm{rpm}$ with PVP concentration of $20 \mathrm{mg} /$ $\mathrm{mL}$; the excessive amount of PVP polymer $(20 \mathrm{mg} / \mathrm{mL})$ might induce drug flocculation and/or aggregation at low milling speed (1200 rpm). Therefore, to obtain a small and uniform particle size of CA nanosuspension, the milling intensity and concentration of the suspending agent was set to $1800 \mathrm{rpm}$ and $5 \mathrm{mg} / \mathrm{mL}$, respectively.

Next, the effect of formulation variables (such as CA content in the preparation or the type of vehicle) on crystal size and homogeneity is shown in Figure 2B. Both DW and the mixture of DW and BG $(1: 1 \mathrm{v} / \mathrm{v})$ were screened as dispersion media with different drug concentrations (10, 50 , and $100 \mathrm{mg} / \mathrm{mL}$ ). Co-solvents such as $\mathrm{BG}$, propylene glycol, or glycerin are occasionally included in the
A

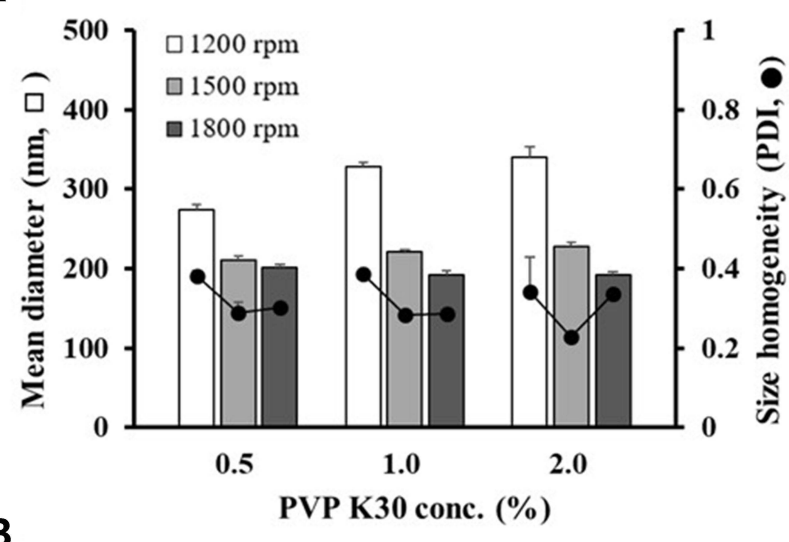

B

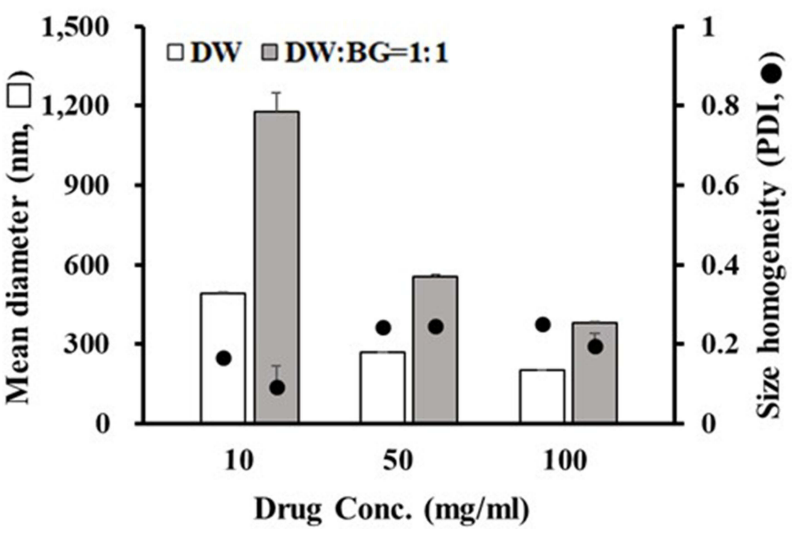

Figure 2 Effect of formulation variables on the median diameter and homogeneity of nanocrystals fabricated using bead-milling technology. (A) Effect of PVP K30 concentration and milling speed on the crystal size and homogeneity; (B) Effect of CA concentration and aqueous vehicle (DW and BG $50 \mathrm{v} / \mathrm{v} \%$ solution) on the crystal size and homogeneity.

Notes: (A) CA concentration and milling time were fixed to $100 \mathrm{mg} / \mathrm{mL}$ and $4 \mathrm{~h}$, respectively. (B) PVP K30 concentration, milling speed, and milling time were fixed to $5 \mathrm{mg} / \mathrm{mL}$, $1800 \mathrm{rpm}$, and $4 \mathrm{~h}$, respectively. Three batches of each sample were prepared, and the data are presented as mean $\pm S D(n=3)$.

Abbreviations: CA, Centella asiatica; DW, distilled water; BG, butylene glycol.

external preparations to improve skin moisturizing effects and/or the spreading of drug nanoparticles over the skin. $^{52,53}$ The solubility of AA and MA in the DW and BG mixture $(1: 1 \mathrm{v} / \mathrm{v})$ was about $0.7 \mathrm{mg} / \mathrm{mL}$ and $0.1 \mathrm{mg} /$ $\mathrm{mL}$, respectively, which was approximately $8.2-$ and 6.7-folds higher than that in phosphate buffer (AA, 85 $\mu \mathrm{g} / \mathrm{mL}$; and $\mathrm{MA}, 15 \mu \mathrm{g} / \mathrm{mL}$, respectively) (data not shown). As shown in Figure 2B, the particle size tended to decrease as the concentration of CA increased. When DW was employed as a dispersion medium, the drug particle size of NSs prepared using CA concentrations of 10,50 , and $100 \mathrm{mg} / \mathrm{mL}$ was estimated to 493,268 , and $201 \mathrm{~nm}$. This tendency was more prominent when using DW and BG mixture $(1: 1 \mathrm{v} / \mathrm{v})$; the particle size of NSs with CA content of 10,50 , and $100 \mathrm{mg} / \mathrm{mL}$ were determined to be 1178,576 , and $376 \mathrm{~nm}$, respectively. Decrease 
in initial CA dosing or increased drug solubility by addition of $\mathrm{BG}$ resulted in the reduction of solid-state drug particles in the vehicle. Consequently, the polymeric suspending agent might exceed the optimal concentration, contributing to the association and/or aggregation of $\mathrm{CA}$ crystals. This result coincided with the increase in particle size with increasing PVP concentration (Figure 2A). Particularly, the addition of BG might interfere with the interaction between the hydrophilic polymer and drug particles and adsorption on the surface, resulting in particle aggregation and increase in particle size.

\section{Validation of HPLC Assay of AS, AA, and MA}

The established HPLC analytical methods to determine the AS, AA, and MA content were inter-day validated (Table 2). The assay showed excellent selectivity for retention time of 5.7, 7.6, and $8.3 \mathrm{~min}$ for $\mathrm{AS}, \mathrm{AA}$, and MA, respectively. Additionally, it showed excellent linearity between analyte concentration and the area under the peak, in the ranges of 5-100, 10-100, and 10-100 $\mu \mathrm{g} / \mathrm{mL}$ of AS, AA, and MA, respectively. The LOQs for AS, AA, and MA were estimated to about 4.0, 7.0, and 5.8, respectively, ensuring the quantification of low levels of active compounds in samples (Table 2). The accuracy and precision of the established HPLC methods were also intervalidated. Accuracy, estimated by dividing the calculated concentration by nominal concentration, for all the tested

Table 2 Inter-Day Validation of HPLC Methods for AS, AA, and MA

\begin{tabular}{|c|c|c|c|}
\hline & AS & AA & MA \\
\hline Accuracy (\%) $^{\mathrm{a}}$ & & & \\
$5 \mu \mathrm{gL}$ & 101.4 & N.D. ${ }^{\mathrm{b}}$ & 103.5 \\
$10 \mu \mathrm{g} / \mathrm{mL}$ & 97.5 & 98.4 & 103.3 \\
$25 \mu \mathrm{mL}$ & 101.6 & 100.5 & 102.8 \\
$100 \mu \mathrm{g} / \mathrm{mL}$ & 99.6 & 99.7 & 100.3 \\
\hline Precision (\%) & & & \\
$5 \mu \mathrm{c} / \mathrm{mL}$ & 2.25 & N.D. & 1.62 \\
$10 \mu \mathrm{g} / \mathrm{mL}$ & 3.90 & 3.70 & 2.83 \\
$25 \mu \mathrm{mL}$ & 2.00 & 1.58 & 2.00 \\
$100 \mu \mathrm{g} / \mathrm{mL}$ & 2.37 & 2.46 & 2.74 \\
\hline LOD $(\mu \mathrm{gg} / \mathrm{mL})$ & 1.32 & 1.90 & 1.90 \\
\hline LOQ $(\mu \mathrm{gg} / \mathrm{mL})$ & 4.01 & 5.75 & 5.75 \\
\hline
\end{tabular}

Notes: ${ }^{a}$ Calculated using the following formula: concentration/nominal concentration $\times 100$; ${ }^{b}$ not determined; ${ }^{c}$ standard deviation of calculated concentration/average of calculated concentration) $\times 100$.

Abbreviations: $A S$, asiaticoside; AA, asiatic acid; MA, madecassic acid; LOD, limit of detection; LOQ, limit of quantification. concentrations was in the range of $97.5 \%$ to $103.5 \%$ for AS, AA, and MA. Additionally, the relative standard deviation representing the precision of the analytical methods was below $4.0 \%$ in all concentrations of $\mathrm{AS}, \mathrm{AA}$, and MA. Thus, the established HPLC methods were employed to evaluate the drug content, in vitro release profile, and skin permeation and retention following topical application.

\section{Morphological and Physical Characteristics of CA NSs}

Based on the aforementioned formulation study, we designed four different NS formulations and the physicochemical properties were characterized on the basis of appearance, drug content, particle size, and crystallinity (Table 3 and Figure 3). Specifically, NSs with different CA content $(1.0,5.0$, and $10 \% \mathrm{w} / \mathrm{v})$ were fabricated using $0.5 \%$ PVP K30 as dispersing agent, in DW (named 1\% NS, $5 \% \mathrm{NS}$, and $10 \% \mathrm{NS}-1$, respectively). Additionally, NS composed of $10 \% \mathrm{CA}$ and $0.5 \%$ PVP K30, in a mixture of DW and BG (1:1) (ie, 10\%NS-2), was exploited to further evaluate the effect of co-solvent on skin absorption of CA.

All NS formulations were uniform in appearance, and the content of AS, AA, and MA in preparations increased proportionally as the CA content increased from $1 \%(\mathrm{w} / \mathrm{v})$ to $10 \%(\mathrm{w} / \mathrm{v})$. The content of AS in $1 \% \mathrm{NS}, 5 \% \mathrm{NS}$, and $10 \%$ NS-1 increased proportionally to $3.49,17.2$, and $33.8 \mathrm{mg} / \mathrm{mL}$, respectively (Table 3 ). Additionally, the total content of aglycones such as MA or AA increased to $5.7,25.6$, and $49.1 \mathrm{mg} / \mathrm{mL}$, respectively. This indicates that the loading of poorly water-soluble compound in an aqueous vehicle could be remarkably improved using nanocrystallization technique, by evenly suspending the submicronized solid-state drug particles in an aqueous vehicle. As observed earlier, the particle size tended to decrease as CA content in the vehicle increased from $1 \%$ to $5 \%$ or $10 \%$; the crystal size in $1 \% \mathrm{NS}, 5 \% \mathrm{NS}$ and $10 \%$ NS was determined to be 493, 268 and $201 \mathrm{~nm}$, respectively. The addition of BG further increased the particle size; the particle size of $10 \% \mathrm{NS}-2$ was estimated to 379.4 $\mathrm{nm}$. Nevertheless, the particle size was maintained below $500 \mathrm{~nm}$, providing high saturated solubility and rapid diffusion compared to micronized particles. In a previous report, nanocrystals with a size range of $200-400 \mathrm{~nm}$ enhanced permeability across the skin and mucosal membranes by enhancing the saturation solubility and consequently, facilitated dissolution rate with reduced diffusional distance. ${ }^{54,55}$ Nanocrystals below $500 \mathrm{~nm}$ in size penetrate the skin through the hair follicles and are 
Table 3 Physicochemical Characteristics of the CA-Loaded NS Formulations and Marketed Product (Madeca Cream)

\begin{tabular}{|c|c|c|c|c|c|}
\hline & I\%NS & $5 \%$ NS & I0\%NS-I & $10 \%$ NS-2 & Madeca Cream ${ }^{\mathrm{b}}$ \\
\hline \multicolumn{6}{|l|}{ Compositions } \\
\hline CA (mg) & 10.0 & 50.0 & 100.0 & 100.0 & \\
\hline PVP K30 (mg) & 5.0 & 5.0 & 5.0 & 5.0 & \\
\hline BG $(m L)$ & - & - & - & 0.5 & \\
\hline $\mathrm{DW}(\mathrm{mL})$ & 1.0 & 1.0 & 1.0 & 0.5 & \\
\hline \multicolumn{6}{|c|}{ Physicochemical characteristics } \\
\hline AS content $(\mathrm{mg} / \mathrm{mL})^{\mathrm{a}}$ & $3.49 \pm 0.03$ & $17.19 \pm 0.48$ & $33.75 \pm 0.12$ & $29.90 \pm 0.66$ & $2.77 \pm 0.04$ \\
\hline MA content $(\mathrm{mg} / \mathrm{mL})^{\mathrm{a}}$ & $3.25 \pm 0.02$ & $15.44 \pm 0.67$ & $30.37 \pm 1.16$ & $26.90 \pm 0.04$ & $3.03 \pm 0.20$ \\
\hline AA content $(\mathrm{mg} / \mathrm{mL})^{\mathrm{a}}$ & $2.49 \pm 0.01$ & $10.23 \pm 0.32$ & $18.79 \pm 0.74$ & $15.43 \pm 0.08$ & $1.72 \pm 0.21$ \\
\hline Particle size $(\mathrm{nm})^{\mathrm{a}}$ & $493.5 \pm 0.8$ & $268.4 \pm 2.1$ & $201.4 \pm 5.0$ & $379.4 \pm 6.3$ & $-^{c}$ \\
\hline Homogeneity (PDI) $^{\mathrm{a}}$ & $0.17 \pm 0.01$ & $0.24 \pm 0.00$ & $0.24 \pm 0.01$ & $0.20 \pm 0.30$ & $-^{c}$ \\
\hline $\mathrm{pH}^{\mathrm{a}}$ & $5.72 \pm 0.07$ & $5.40 \pm 0.01$ & $5.32 \pm 0.05$ & $5.65 \pm 0.01$ & $-^{c}$ \\
\hline
\end{tabular}

Notes: a Data are expressed as mean \pm SD ( $n=3)$; ${ }^{\text {b}}$ The exact composition of Madeca cream is unknown, and only the content of AS, MA, and AA contained in cream formula was evaluated; 'Not determined.

Abbreviations: CA, Centella asiatica; BG, butylene glycol; NS, nanocrystal suspensions; AS, asiaticoside; AA, asiatic acid; MA, madecassic acid.

subsequently absorbed by the surrounding follicular epithelium. ${ }^{31}$ Moreover, nanocrystals with an appropriate size (approximately $700 \mathrm{~nm}$ ) can deposit into follicles and appendages, which act as a reservoir continuously delivering the therapeutic agent to the surrounding tissues. ${ }^{56}$

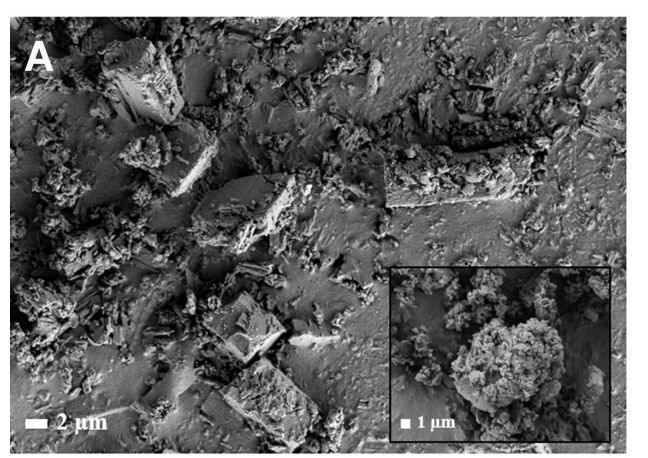

C

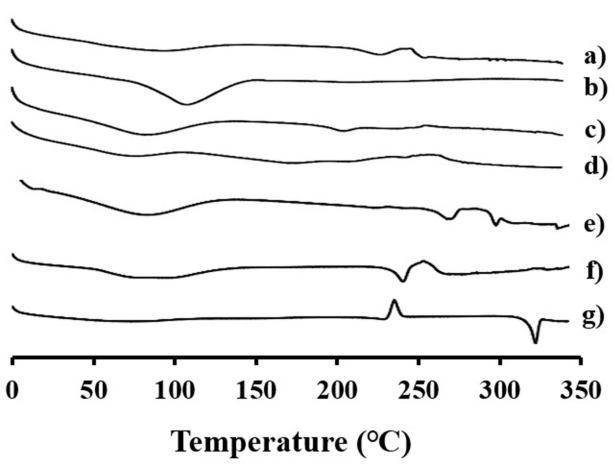

The morphological features of nanocrystals suspended in the aqueous vehicle were scrutinized using TEM. In NS system, nanocrystals prepared using bead-milling technique were spherical and/or elliptical (Figure 3B). Subsequently, the crystalline state of the nanocrystals in

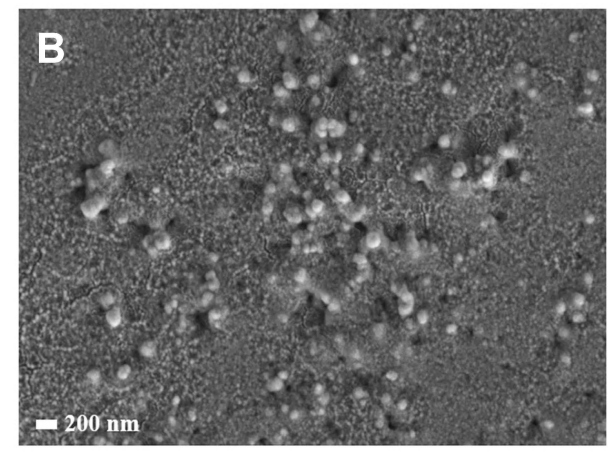

D

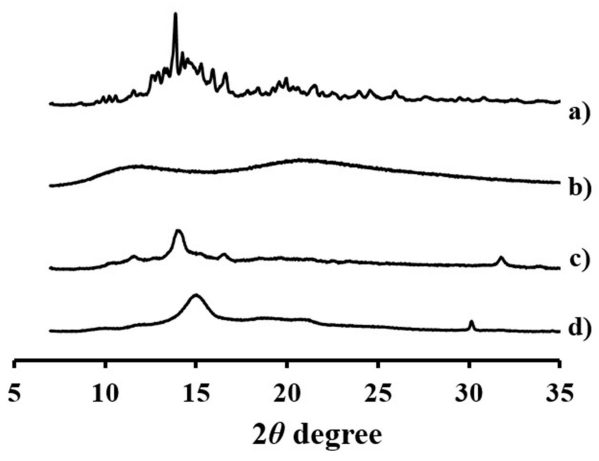

Figure 3 Morphological and physical characteristics of CA-loaded NS. Representative microscopic images of (A) CA raw material, and (B) high-payload NS (I0\%NS-I). (C) DSC curves of (a) raw material, (b) CA-free vehicle, (c) 10\%NS-I, (d) 10\%NS-2, (e) MA, (f) AS, and (g) AA. (D) XRD patterns of (a) raw material, (b) CA-free vehicle, (c) $10 \%$ NS-I, and (d) $10 \%$ NS-2.

Abbreviations: CA, Centella asiatica; NS, nanocrystal suspensions; DSC, differential scanning calorimeter; MA, madecassic acid; AS, asiaticoside; AA, asiatic acid; XRD, X-ray diffractometer. 
each formulation was evaluated using DSC or XRD. In DSC evaluation (Figure 3C), high-purity MA, AS, and AA powders showed distinctive endothermic peaks (representing melting points) at 270,230 , and $330{ }^{\circ} \mathrm{C}$, respectively (Figure 3C, e-g). These are consistent with the previously reported melting points of individual ingredients. ${ }^{57}$ These endothermic peaks are even smaller in CA raw materials (Figure 3C, a), showing weakened endothermic peaks at $230{ }^{\circ} \mathrm{C}$ and $270{ }^{\circ} \mathrm{C}$. In the $\mathrm{CA}$ raw material obtained by ethanol extraction, various components were fractioned along with the three main components, which might hamper the formation of unique molecular arrangement. The partial crystallinity of the raw materials was further weakened in the NS formulations, exhibiting no distinct endothermic peaks in both $10 \% \mathrm{NS}-1$ and $10 \% \mathrm{NS}-2$ (Figure 3C, c and d). Similarly, XRD analysis revealed that the characteristic refractive peak of CA raw material over $2 \theta$ range between $12^{\circ}$ and $17^{\circ}$ (Figure 3D, a) was deteriorated in $10 \%$ NS-1 and 10\% NS-2 (Figure 3D, $\mathrm{c}$ and d). XRD patterns are shaped by the constructive interference of X-rays beam scattered at specific angles from lattice planes of crystalline materials. ${ }^{58}$ Our results indicate that the intrinsic crystallinity of CA raw material weakened as it was split with the dispersant and occasionally, with co-solvent through bead-milling process.

\section{In vitro Dissolution Profile of CA NSs}

In vitro dissolution profile of each active ingredient from CA-loaded NSs $(1 \% \mathrm{NS}, 5 \% \mathrm{NS}$, and $10 \% \mathrm{NS}-1)$ was comparatively evaluated with that of CA raw material, under sink condition. To provide sufficient solubility of the aglycones in aqueous media, SLS was included in phosphatebuffered saline as a solubilizing agent. The solubility of AA or MA in $0.5 \%$ SLS solution ( $\mathrm{pH} 6.8$ ) was estimated to be $0.5 \mathrm{mg} / \mathrm{mL}$ or $0.4 \mathrm{mg} / \mathrm{mL}$, respectively, which is about 50 or 76 times higher compared to those obtained in pure PBS solution. Above critical micelle concentration $(0.5 \% \mathrm{w} / \mathrm{v})$, the anionic surfactant formed a micelle structure incorporating the hydrophobic compounds in the inner compartment. ${ }^{59}$

Under the sink condition, AA, a hydrophilic compound was rapidly dissolved in aqueous media, exhibiting over $80 \%$ dissolution within $15 \mathrm{~min}$, in both NS and raw material (Figure 4A). The hydrophilic nature of the compound led to rapid dissolution and diffusion from pulverized or intact CA particles. In contrast, dissolution of AA or MA from NS was markedly faster than that of raw material (Figure $4 \mathrm{~B}$ and $\mathrm{C}$ ). The amounts of AA or MA
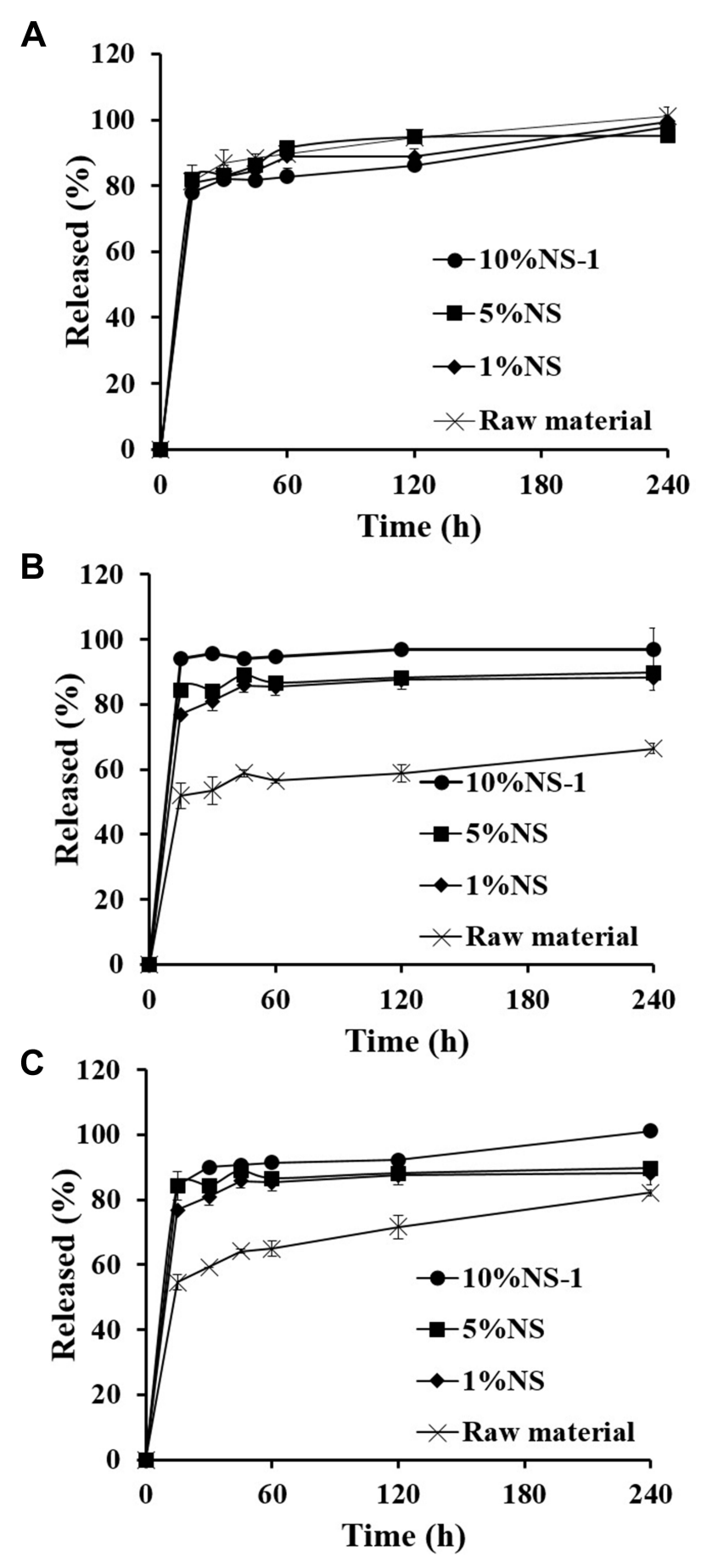

Figure 4 In vitro dissolution profile of (A) AS, (B) AA, and (C) MA from CAloaded NSs, raw material, and the marketed cream formula (Madeca cream) under sink condition.

Notes: Sink condition was provided by adding $1 \%(\mathrm{w} / \mathrm{v})$ of SLS into $10 \mathrm{mM}$ phosphate-buffered saline ( $\mathrm{pH}$ 6.8). Data are expressed as mean $\pm \mathrm{SD}(\mathrm{n}=3)$. Abbreviations: AS, asiaticoside; AA, asiatic acid; MA, madecassic acid; CA, Centella asiatica; NS, nanocrystal suspensions; SLS, sodium lauryl sulfate.

released from the raw material were $53 \%$ and $59 \%$, respectively, after $30 \mathrm{~min}$. Conversely, the amounts of AA and MA liberated from all NS formulas $(1 \% \mathrm{NS}, 5 \% \mathrm{NS}$, and $10 \% \mathrm{NS}-1$ ) within 30 min were over $80 \%$ and over $80 \%$, 
respectively. This profound dissolution of NS under sink condition can be explained by Noyes-Whitney equation; $\mathrm{dM} / \mathrm{dt}=\mathrm{k} \cdot \mathrm{S} \cdot \mathrm{Cs}$, where $\mathrm{dM} / \mathrm{dt}$, dissolution rate; $\mathrm{k}$, rate constant; S, surface area of the drug particle; Cs, drug solubility in dissolution media. The reduction in drug particle size led to a drastically increased surface area, thus enhancing the dissolution rate of hydrophobic compound in dissolution media. ${ }^{60,61}$ Moreover, the disruption of the compacted crystal lattice exposes the internal hydrophobic surface of the crystal to the aqueous medium, increasing saturation solubility determined by OstwaldFreundlich's equation. ${ }^{48,62}$

\section{In vitro Skin Absorption of CA NSs}

In vitro skin permeation and retention of major constituents of CA were evaluated using Franz diffusion cells mounted with porcine skin. Among the wide range of animal models such as pig, mouse, rat, or guinea pig, porcine skin has been widely used in skin absorption studies because of its high histological similarity to human skin, with convenient acquirement. ${ }^{63}$ Despite differences in lipid arrangements between porcine and human stratum corneum, porcine skin is histologically similar to human skin, with comparable thickness $(21-26 \mu \mathrm{m})$ and lipid composition of stratum corneum (SC) with that of human. ${ }^{64-67}$ Additionally, the average hair-follicle density in porcine ear skin is 20 follicles $/ \mathrm{cm}^{2}$ compared to 14-32 follicles $/ \mathrm{cm}^{2}$ in human forehead skin. ${ }^{66}$ To provide a sink condition, SLS was included in the receptor media at the concentration of $0.5 \mathrm{w} / \mathrm{v} \%$. The anionic surfactant has negligible skin perturbation or permeation enhancement effect, at low concentrations. ${ }^{16,68}$ As test group, $1 \% \mathrm{NS}$, $5 \% \mathrm{NS}, 10 \% \mathrm{NS}-1$, and $10 \% \mathrm{NS}-2$ were comparatively evaluated with commercially available cream formula (Madeca cream).

Throughout $24 \mathrm{~h}$ of skin permeation study under sink condition, major constituents of CA (AS, AA, and MA) were not detected in the receptor phase of all formulations including NS or marketed product (data not shown). AS has a high molecular weight of over $950 \mathrm{~g} / \mathrm{mol}$ with hydrophilic properties, which makes its penetration into the stratum corneum difficult. In the case of AA and MA, the extremely lipophilic properties $(\log P$ values of 5.7 and 4.3 , respectively) with the sizable molecular weight hampered the skin permeation, instead being adsorbed and/or deposited in the stratum corneum. This permeation result is consistent with the previous reports. Rocha et al (2019) reported that the topical application of $\mathrm{CA}$ formulated into solid lipid nanoparticles resulted in higher accumulation of AS in the skin layer, but AS was not detected in the receptor media. ${ }^{16} \mathrm{Kim}$ et al (2002) also reported that the three components were not permeated across excised skin of hairless mouse after topical application of niosomal formulation of $\mathrm{CA} .^{17}$

After $24 \mathrm{~h}$ of permeation study, the individual amount of $\mathrm{AS}, \mathrm{AA}$, or MA deposited in the porcine skin was determined (Figure 5). First, the amount of AS, AA, or MA accumulated in the skin after application of $1 \% \mathrm{NS}$ (AS, $3.5 \mathrm{mg} / \mathrm{g}$; AA, $2.5 \mathrm{mg} / \mathrm{mL}$; and MA, $3.3 \mathrm{mg} / \mathrm{mL}$, Table 3) or Madeca cream (AS, $2.8 \mathrm{mg} / \mathrm{g}$; AA, $1.7 \mathrm{mg} / \mathrm{mL}$; and MA, $3.0 \mathrm{mg} / \mathrm{mL}$, Table 3) containing similar quantities of the active ingredient were compared. Madeca Cream contains three components as solubilized state, by employing solubilizers such as dipropylene glycol, caprylic/capric triglyceride, glycerin, glyceryl stearate, cetyl alcohol, and vegetable oils. ${ }^{69}$ In contrast, poorly water-soluble aglycones (AA or MA) were almost contained as solid-state nanocrystals in $1 \% \mathrm{NS}$ formula. Nevertheless, there was no marked difference in the deposition of the three components in skin between $1 \% \mathrm{NS}$ and Madeca cream. After topical application of $1 \% \mathrm{NS}$ and Madeca cream, the amount of AS deposited was 23.5 and $30.5 \mu \mathrm{g} / \mathrm{g}$, respectively. The amounts of AA (9.5 and $6.4 \mu \mathrm{g} / \mathrm{g}$, respectively) or MA (13.7 and $15.3 \mu \mathrm{g} / \mathrm{g}$, respectively) deposited were also analogous between $1 \% \mathrm{NS}$ and Madeca cream. This indicates that, although the hydrophobic components exist in an undissolved state in the NS, active compounds were rapidly dissolved or adsorbed in the relevant skin layer, by forming a high concentration gradient between the hydrogel and the stratum corneum. Moreover, intact CA nanocrystals and/or dissolved molecules might have penetrated into the skin through the surrounding follicular epithelium, exhibiting comparable skin absorption with that of the commercial cream, without using an oily solubilizer or surfactant.

The amount of AS, AA, or MA deposited in the porcine skin after topical application of NS formulations proportionally increased as the content of CA in NS formulations increased from 1 to 5 or $10 \%(\mathrm{w} / \mathrm{v})$. After topical application of $1 \% \mathrm{NS}$, the accumulated amount of $\mathrm{AS}, \mathrm{AA}$, or MA deposited in the skin was 23.5, 9.5, and $13.7 \mu \mathrm{g} / \mathrm{g}$, respectively, whereas those obtained with $5 \%$ NS were $90.9,13.3$, and $60.2 \mu \mathrm{g} / \mathrm{g}$, which is 3.9-, 1.4, and 4.4-folds higher compared to $1 \% \mathrm{NS}$, respectively. The amount of $\mathrm{AS}, \mathrm{AA}$, or MA deposited in the skin was further increased with $10 \% \mathrm{NS}-1$, providing $6.5-$, 2.0-, or 5.0-folds higher accumulation, respectively, in the 
A

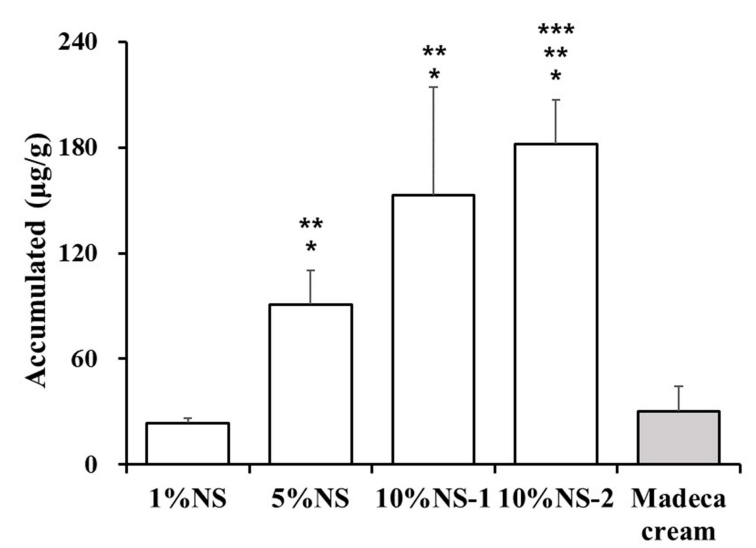

B

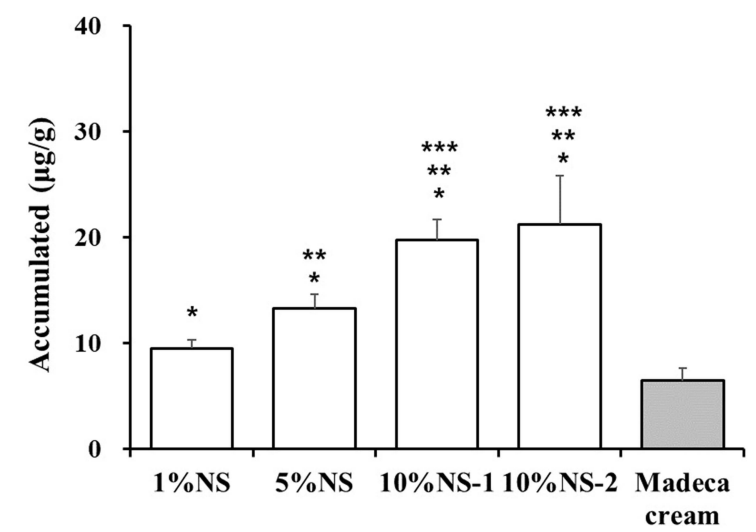

C

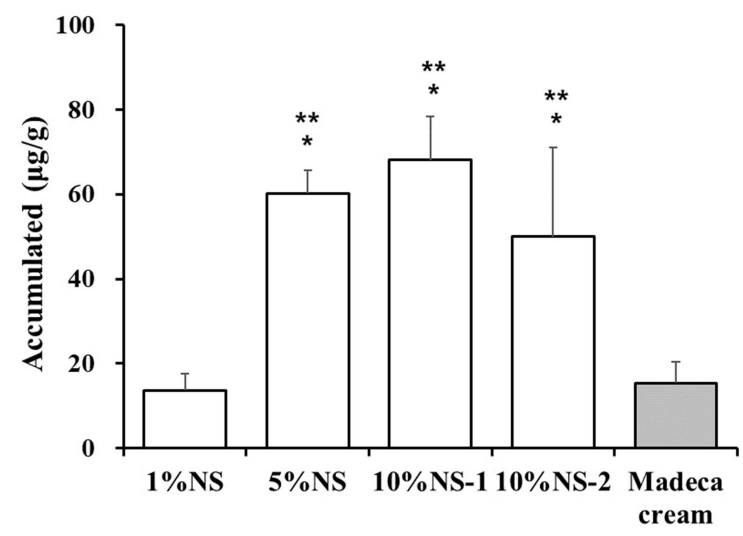

Figure 5 Accumulation of (A) AS, (B) AA, and (C) MA in porcine dorsal skin after $24 \mathrm{~h}$ post-application of CA-loaded NSs (I\%NS, $5 \% \mathrm{NS}, 10 \% \mathrm{NS}-\mathrm{I}$, and $10 \% \mathrm{NS}-2$ ) or the marketed cream formula in a Franz diffusion cell model.

Notes: Data are expressed as mean \pm SD $(n=4)$. Statistical analysis was conducted using one-way ANOVA test. ${ }^{*} p<0.05$, compared to Madeca cream; $* * p<0.05$, compared to $1 \% \mathrm{NS}$; ***p $<0.05$, compared to $5 \% \mathrm{NS}$.

Abbreviations: AS, asiaticoside; AA, asiatic acid; MA, madecassic acid; CA, Centella asiatica; NS, nanocrystal suspensions.

biological membrane compared to that achieved with $1 \%$ NS. Moreover, the amount of AS, AA, or MA accumulated in skin with $10 \% \mathrm{NS}-1$ was approximately $1.7-, 1.5-$, or 1.1-fold higher than those obtained from 5\% NS, respectively. This indicates that the increase in CA loading in the preparation resulted in an elevated concentration gradient between the formulation and skin layer, leading to an elevated diffusive flux value and thus, promoting higher accumulation of active constituents in the skin layer.

Next, the amount of the three constituents after application of $10 \% \mathrm{NS}-1$ or $10 \% \mathrm{NS}-2$ were compared to evaluate the effect of co-solvent on skin absorption of CA. Cosolvents, including BG, are commonly employed in external preparations and are reported to act as humectants, hydrating the outer layer of the skin. Moreover, it dissolves active ingredients and improves penetration into the hydrated skin. ${ }^{52,53}$ However, in our study, there was no significant difference in the skin absorption between $10 \%$ NS- 1 and $10 \%$ NS- 2 group; the amount of AS, AA, and MA in the $10 \% \mathrm{NS}-1$ group was $152.9 \mu \mathrm{g} / \mathrm{g}, 19.7 \mu \mathrm{g} / \mathrm{g}$, and $68.1 \mu \mathrm{g} / \mathrm{g}$, respectively, and that in the $10 \% \mathrm{NS}-2$ group was $182 \mu \mathrm{g} / \mathrm{g}, 21.2 \mu \mathrm{g} / \mathrm{g}$, and $50.0 \mu \mathrm{g} / \mathrm{g}$, respectively. This suggests that the concentration gradient between the formulation and skin layer had a greater effect on the skin absorption of the three components compared to the type of vehicle. Additionally, the increase in particle size in the presence of co-solvent might hamper the dissolution and/or penetration of NSs into the skin.

\section{In vivo Skin Irritation of High-Payload NS of CA}

Skin irritation of high-payload NSs $(10 \%$ NS-1 or $10 \%$ NS2) was assessed in normal rats, in accordance with the OECD Guidelines 404: Acute dermal irritation/ corrosion. $^{46}$ Studies on skin irritation and/or sensitization are essential to gauge local tolerability or potential hazards of the CA high-payload preparations. The negative control group received $\mathrm{CA}$-free vehicle, and the positive control group received the marketed cream (Madeca cream, CA $1.0 \%(\mathrm{w} / \mathrm{v}))$. As shown in Figure 6, no skin irritations such as erythema or oedema were observed in any of the treated groups during 5 days of the experimental period. Accordingly, when erythema and oedema were scored on a scale of 0-4 according to the OECD guideline, the scores were reported to be zero in all groups (Table 4). The tolerability of topical CA is consistent with the previous report that no macroscopic cutaneous reactions attributable to allergy were observed after $24 \mathrm{~h}$ occlusive dressing of $50 \% \mathrm{CA}$ in paraffin oil in guinea pigs. ${ }^{70}$ Therefore, the high-payload NS system could be an effective tool to improve skin absorption by increasing the concentration gradient without any skin irritation and/or sensitization. 

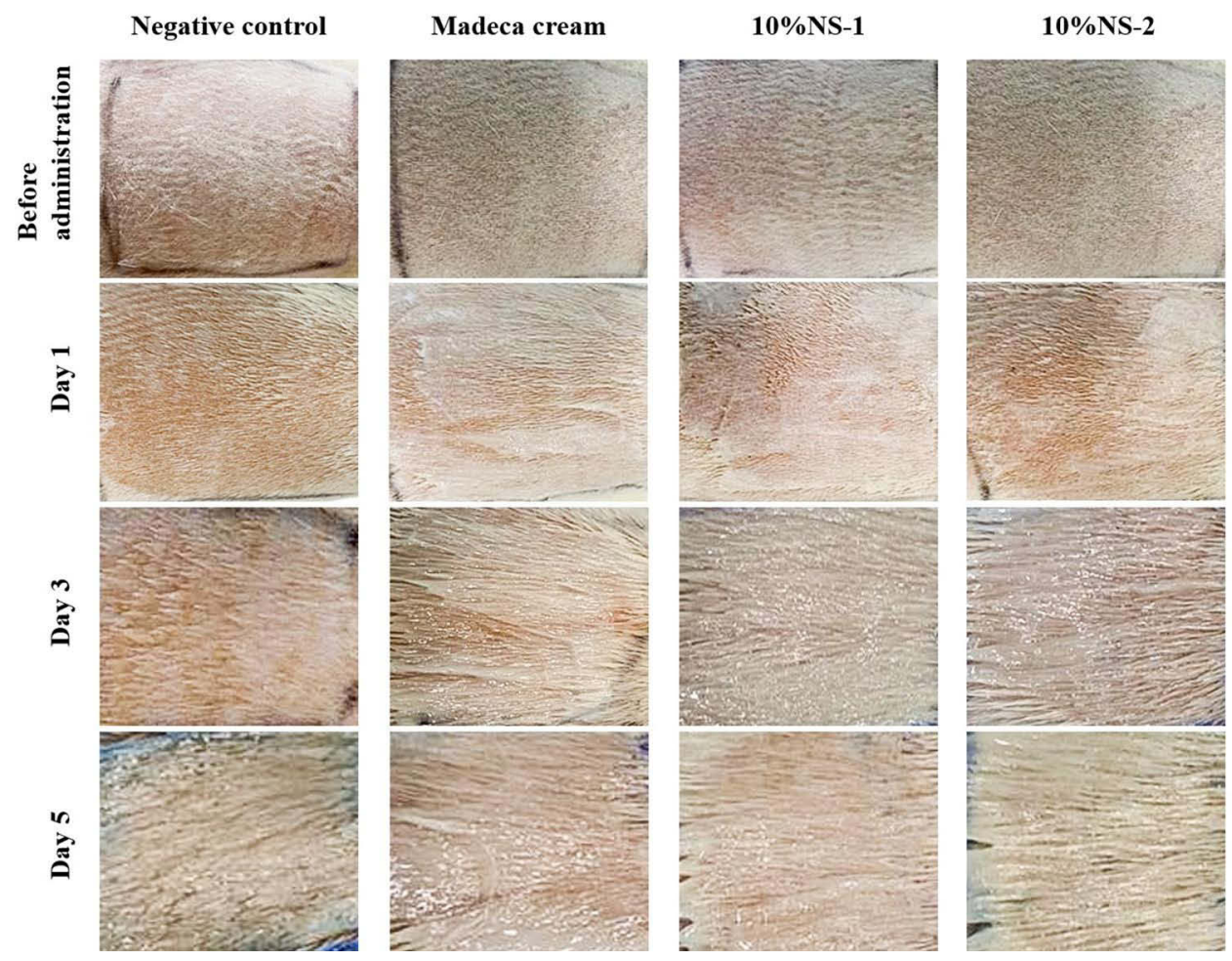

Figure 6 Representative images of dorsal skin of normal rats after daily application of CA-free vehicle, high-payload NSs (I0\%NS-I or 10\%NS-2), or marketed cream for 5 days. Abbreviations: CA, Centella asiatica; NS, nanocrystal suspensions.

\section{Conclusion}

In this study, novel high-payload topical preparation of CA was successfully prepared using nanocrystal technology, which improved the loading capacity of the preparation and the skin absorption of active compounds such as, AA,

Table 4 Scoring of Severity of Erythema or Oedema After Topical Daily Application of Vehicle, High-Payload NSs (10\%NSI and 10\%NS-2), or the Marketed Cream Onto the Dorsal Legion of Normal Rats ( $n=5$ per Each Group)

\begin{tabular}{|c|c|c|c|c|}
\hline & Vehicle & I0\%NS-I & I0\%NS-2 & Madeca Cream \\
\hline Erythema & & & & 0 \\
Day I & 0 & 0 & 0 & 0 \\
Day 2 & 0 & 0 & 0 & 0 \\
Day 3 & 0 & 0 & 0 & 0 \\
Day 4 & 0 & 0 & 0 & 0 \\
Day 5 & 0 & 0 & 0 & \\
\hline Oedema & & & & 0 \\
Day I & 0 & 0 & 0 & 0 \\
Day 2 & 0 & 0 & 0 & 0 \\
Day 3 & 0 & 0 & 0 & 0 \\
Day 4 & 0 & 0 & 0 & 0 \\
Day 5 & 0 & 0 & 0 & 0 \\
\hline
\end{tabular}

Note: Data are expressed as the sum of individual scores. Abbreviation: NS, nanocrystal suspensions. and MA. The NS was lucratively prepared using wetmilling technique by adjusting the type and amount of steric stabilizer, CA content, and milling speed. The optimized NS system, composed of 10\% CA, 0.5\% PVP K30 as steric stabilizer, and $89.5 \%$ of $\mathrm{DW}$, is characterized as follows: spherical or elliptical shape, $200 \mathrm{~nm}$ in size, with low crystallinity. The release rate of both AA and MA from $\mathrm{NC}$ was markedly faster compared to that from raw material, under sink condition. Accumulation of both hydrophilic (AS) and hydrophobic (AA or MA) constituents into skin layer was markedly elevated as the content of CA increased in the preparation, providing 5-, 4-, and 4.5-fold higher accumulation of AS, AA, and MA, compared to that of the commercially available cream. Moreover, the high-payload system of CA was tolerable, showing neither erythema nor oedema in a normal rat model. Therefore, the novel NS system can be a sound approach for improved skin delivery of CA without any skin irritation or need of surfactants.

\section{Acknowledgments}

This research was supported by Basic Science Research Program through the National Research Foundation of Korea (NRF) funded by the Ministry of Science, ICT \& Future Planning (NRF-2019R1C1C1004211). 


\section{Disclosure}

The authors report no conflicts of interest for this work.

\section{References}

1. Camacho-Alonso F, Torralba-Ruiz MR, Garcia-Carillo N, LacalLujan J, Martinez-Diaz F, Sanchez-Siles M. Effects of topical applications of porcine acellular urinary bladder matrix and Centella asiatica extract on oral wound healing in a rat model. Clin Oral Investig. 2019;23(5):2083-2095. doi:10.1007/s00784-018-2620-x

2. Aziz HA, Taher M, Sulaiman WMAW, Susanti D, Chowdhury SR, Zakaria ZA. In vitro and in vivo wound healing studies of methanolic fraction of Centella asiatica extract. S Afr J Bot. 2017;108:163-174. doi:10.1016/j.sajb.2016.10.022

3. Yao CH, Yeh JY, Chen YS, Li MH, Huang CH. Wound-healing effect of electrospun gelatin nanofibres containing Centella asiatica extract in a rat model. $J$ Tissue Eng Regen Med. 2017;11(3):905-915. doi:10.1002/term.1992

4. Lu L, Ying K, Wei S, Liu Y, Lin H, Mao Y. Dermal fibroblast-associated gene induction by asiaticoside shown in vitro by DNA microarray analysis. Br J Dermatol. 2004;151(3):571-578. doi:10.1111/j.1365-2133.2004.06146.x

5. Bylka W, Znajdek-Awiżeń P, Studzińska-Sroka E, Brzezińska M. Centella asiatica in cosmetology. Adv Dermatol Allergol. 2013; 30:46-49. doi:10.5114/pdia.2013.33378

6. Gray NE, Alcazar MA, Lak P, et al. Centella asiatica: phytochemistry and mechanisms of neuroprotection and cognitive enhancement. Phytochem Rev. 2017;17(1):161-194. doi:10.1007/s11101-017-9528-y

7. Lu L, Ying K, Wei S, et al. Asiaticoside induction for cell-cycle progression, proliferation and collagen synthesis in human dermal fibroblasts. Int $J$ Dermatol. 2004;43(11):801-807. doi:10.1111/ j.1365-4632.2004.02047.x

8. Lee J, Jung E, Kim Y, et al. Asiaticoside induces human collagen I synthesis through TGFbeta receptor I kinase (TbetaRI kinase)-independent Smad signaling. Planta Med. 2006;72 (4):324-328. doi:10.1055/s-2005-916227

9. Ratz-łyko A, Arct J, Pytkowska K. Moisturizing and antiinflammatory properties of cosmetic formulations containing centella asiatica extract. Indian J Pharm Sci. 2016;78(1):27-33. doi:10.4103/0250474x. 180247

10. Shukla A, Rasik AM, Dhawan BN. Asiaticoside-induced elevation of antioxidant levels in healing wounds. Phytother Res. 1999;13(1):50-54. doi:10.1002/(SICI)1099-1573(199902)13:1<50::AID-PTR368>3.0. $\mathrm{CO} ; 2-\mathrm{V}$

11. Flynn TC, Petros J, Clark RE, Viehman GE. Dry skin and moisturizers. Clin Dermatol. 2001;19(4):387-392. doi:10.1016/ S0738-081X(01)00199-7

12. Godin B, Touitou E. Transdermal skin delivery: predictions for humans from in vivo, ex vivo and animal models. Adv Drug Deliv Rev. 2007;59(11):1152-1161. doi:10.1016/j.addr.2007.07.004

13. Ruela ALM, Perissinato AG, de Lino MES, Mudrik PS, Pereira GR. Evaluation of skin absorption of drugs from topical and transdermal formulations. Braz J Pharm Sci. 2016;52(3):527-544. doi:10.1590/ s1984-82502016000300018

14. Anissimov YG, Jepps OG, Dancik Y, Roberts MS. Mathematical and pharmacokinetic modelling of epidermal and dermal transport processes. Adv Drug Deliv Rev. 2013;65:169-190.

15. Jepps OG, Dancik Y, Anissimov YG, Roberts MS. Modeling the human skin barrier-Towards a better understanding of dermal absorption. $A d v$. Drug Deliv Rev. 2013;65(2):152-168. doi:10.1016/j.addr.2012.04.003

16. da Rocha PBR, Dos Santos B, Andrade LM, et al. Enhanced asiaticoside skin permeation by Centella asiatica-loaded lipid nanoparticles: effects of extract type and study of stratum corneum lipid dynamics. J Drug Deliv Sci Technol. 2019;50:305-312. doi:10.1016/j. jddst.2019.01.016
17. Kim D, Cho M, Park S, et al. Preparation and evaluation of titrated extract of centella asiatica niosome/W/O system cream for site specific targeting. $J$ Pharm Investig. 2002;32:291-297.

18. Liu M, Chen W, Zhang X, et al. Improved surface adhesion and wound healing effect of madecassoside liposomes modified by temperature-responsive PEG-PCL-PEG copolymers. Eur J Pharm Sci. 2020;151:105373. doi:10.1016/j.ejps.2020.105373

19. Wichayapreechar P, Anuchapreeda S, Phongpradist R, Rungseevijitprapa W, Ampasavate C. Dermal targeting of Centella asiatica extract using hyaluronic acid surface modified niosomes. J Liposome Res. 2020;30(2):197-207. doi:10.1080/08982104.2019. 1614952

20. Effendy I, Maibach HI. Surfactants and experimental irritant contact dermatitis. Contact Derm. 1995;33(4):217-225. doi:10.1111/j.16000536.1995.tb00470.x

21. Wang Y, Wang S, Xu Y, et al. Etoposide amorphous nanopowder for improved oral bioavailability: formulation development, optimization, in vitro and in vivo evaluation. Int $J$ Nanomed. 2020;15: 7601-7613. doi:10.2147/IJN.S265817

22. Pireddu R, Sinico C, Ennas G, et al. Novel nanosized formulations of two diclofenac acid polymorphs to improve topical bioavailability. Eur J Pharm Sci. 2015;77:208-215. doi:10.1016/j. ejps.2015.06.006

23. Im S, Jung H, Ho M, et al. Montelukast nanocrystals for transdermal delivery with improved chemical stability. Pharmaceutics. 2019;12 (1):18. doi:10.3390/pharmaceutics 12010018

24. Pawar VK, Singh Y, Meher JG, Gupta S, Chourasia MK. Engineered nanocrystal technology: in-vivo fate, targeting and applications in drug delivery. J Control Release. 2014;183:51-66.

25. Aref ZF, Bazeed SEES, Hassan MH, et al. Clinical, biochemical and molecular evaluations of ivermectin mucoadhesive nanosuspension nasal spray in reducing upper respiratory symptoms of mild COVID-19. Int J Nanomed. 2021;16:4063-4072. doi:10.2147/IJN. S313093

26. Gao L, Zhang D, Chen M. Drug nanocrystals for the formulation of poorly soluble drugs and its application as a potential drug delivery system. J Nanopart Res. 2008;10(5):845-862. doi:10.1007/s11051008-9357-4

27. Junyaprasert VB, Morakul B. Nanocrystals for enhancement of oral bioavailability of poorly water-soluble drugs. Asian J Pharm Sci. 2015;10(1):13-23. doi:10.1016/j.ajps.2014.08.005

28. Chen L, Wang Y, Zhang J, et al. Bexarotene nanocrystal-Oral and parenteral formulation development, characterization and pharmacokinetic evaluation. Eur J Pharm Biopharm. 2014;87(1):160-169. doi:10.1016/j.ejpb.2013.12.005

29. Zhai X, Lademann J, Keck CM, Müller RH. Dermal nanocrystals from medium soluble actives-physical stability and stability affecting parameters. Eur J Pharm Biopharm. 2014;88(1):85-91. doi:10.1016/ j.ejpb.2014.07.002

30. Chen Y, Liu Y, Xie J, et al. Nose-to-brain delivery by nanosuspensions-based in situ gel for breviscapine. Int $J$ Nanomed. 2020;15:10435-10451. doi:10.2147/IJN.S265659

31. Patzelt A, Richter H, Knorr F, et al. Selective follicular targeting by modification of the particle sizes. J Control Release. 2011;150 (1):45-48. doi:10.1016/j.jconrel.2010.11.015

32. Liversidge GG, Cundy KC. Particle size reduction for improvement of oral bioavailability of hydrophobic drugs: absolute oral bioavailability of nanocrystalline danazol in beagle dogs. Int $J$ Pharm. 1995;125(1):91-97. doi:10.1016/0378-5173(95)00122-Y

33. Huang T, Wang Y, Shen Y, et al. Preparation of high drug-loading celastrol nanosuspensions and their anti-breast cancer activities in vitro and in vivo. Sci Rep. 2020;10(1):8851. doi:10.1038/s41598020-65773-9

34. Steiner D, Bunjes H. Influence of process and formulation parameters on the preparation of solid lipid nanoparticles by dual centrifugation. Int J Pharm. 2021;3:100085. doi:10.1016/j.ijpx.2021.100085 
35. Hagedorn M, Liebich L, Bögershausen A, et al. Rapid development of API nano-formulations from screening to production combining dual centrifugation and wet agitator bead milling. Int J Pharm. 2019;565:187-198. doi:10.1016/j.ijpharm.2019.04.082

36. Erdoğar N, Akkın S, Nielsen TT, et al. Development of oral aprepitant-loaded chitosan-polyethylene glycol-coated cyclodextrin nanocapsules: formulation, characterization, and pharmacokinetic evaluation. J Pharm Investig. 2021;51(3):297-310. doi:10.1007/ s40005-020-00511-x

37. Shamarekh KS, Gad HA, Soliman ME, et al. Towards the production of monodisperse gelatin nanoparticles by modified one step desolvation technique. J Pharm Investig. 2020;50(2):189-200. doi:10.1007/ s40005-019-00455-x

38. Günther B, Wagner H. Quantitative determination of triterpenes in extracts and phytopreparations of Centella asiatica (L.) Urban. Phytomedicine. 1996;3(1):59-65. doi:10.1016/S0944-7113(96)80011-0

39. Wang C, Zhao Y, Yang R, et al. Simultaneous analysis of five triterpenes in Centella asiatica by high performance liquid chromatography with cyclodextrins as the mobile phase additives. Sci Rep 2020;10:18577. doi:10.1038/s41598-020-75554-Z

40. Rafamantanana MH, Rozet E, Raoelison GE, et al. An improved HPLC-UV method for the simultaneous quantification of triterpenic glycosides and aglycones in leaves of Centella asiatica (L.) Urb (APIACEAE). J Chromatogr B Analyt Technol Biomed Life Sci. 2009;877(23):2396-2402. doi:10.1016/j.jchromb.2009.03.018

41. Yu Q, Wu X, Zhu Q, et al. Enhanced transdermal delivery of meloxicam by nanocrystals: preparation, in vitro and in vivo evaluation. Asian J Pharm Sci. 2018;13(6):518-526. doi:10.1016/j.ajps.2017.10.004

42. Pandey KU, Joshi A, Dalvi SV. Evaluating the efficacy of different curcumin polymorphs in transdermal drug delivery. J Pharm Investig. 2021;51(1):75-84. doi:10.1007/s40005-020-00496-7

43. Lin C, Fang C, Al-suwayeh S, et al. In vitro and in vivo percutaneous absorption of seleno-L-methionine, an antioxidant agent, and other selenium species. Acta Pharmacol Sin. 2011;32(9):1181-1190. doi:10.1038/aps.2011.89

44. Winnicka K, Wroblewska M, Sosnowska K, Car H, Kasacka I. Evaluation of cationic polyamidoamine dendrimers' dermal toxicity in the rat skin model. Drug Des Devel Ther. 2015;9:1367-1377. doi:10.2147/DDDT.S78336

45. Barakat NS. Evaluation of glycofurol-based gel as a new vehicle for topical application of naproxen. AAPS Pharm Sci Tech. 2010;11 (3):1138-1146. doi:10.1208/s12249-010-9485-x

46. OECD Guidelines for the Testing of Chemicals. Section 4: Health Effects Test No. 404: Acute Dermal Irritation/Corrosion. Paris: OECD Publishing; 2015.

47. Liedtke S, Wissing S, Müller RH, Mäder K. Influence of high pressure homogenisation equipment on nanodispersions characteristics. Int J Pharm. 2000;196(2):183-185. doi:10.1016/ S0378-5173(99)00417-2

48. Jacob S, Nair AB, Shah J. Emerging role of nanosuspensions in drug delivery systems. Biomater Res. 2020;24(1):3. doi:10.1186/s40824020-0184-8

49. Niwa T, Miura S, Danjo K. Universal wet-milling technique to prepare oral nanosuspension focused on discovery and preclinical animal studiesdevelopment of particle design method. Int J Pharm. 2011;405(12):218-227. doi:10.1016/j.ijpharm.2010.12.013

50. Ziller KH, Rupprecht H. Control of crystal growth in drug suspensions: 1 Design of a control unit and application to Acetaminophen suspensions. Drug Dev Ind Pharm. 1988;14(15-17):2341-2370. doi:10.3109/03639048809152019

51. Nair B. Final report on the safety assessment of polyvinylpyrrolidone (PVP). Int J Toxicol. 2017;36(2):14-58.

52. Watkinson RM, Guy RH, Hadgraft J, Lane ME. Optimisation of cosolvent concentration for topical drug delivery - II: influence of propylene glycol on ibuprofen permeation. Skin Pharmacol Physiol. 2009;22(4):225-230. doi:10.1159/000231528
53. Baba H, Takahara J, Yamashita F, Hashida M. Modeling and prediction of solvent effect on human skin permeability using support vector regression and random Forest. Pharm Res. 2015;32 (11):3604-3617. doi:10.1007/s11095-015-1720-4

54. Pireddu R, Caddeo C, Valenti D, et al. Diclofenac acid nanocrystals as an effective strategy to reduce in vivo skin inflammation by improving dermal drug bioavailability. Colloids Surf B Biointerfaces. 2016;143:64-70. doi:10.1016/j.colsurfb.2016.03.026

55. Li Y, Wang D, Lu S, et al. Pramipexole nanocrystals for transdermal permeation: characterization and its enhancement micro-mechanism. Eur J Pharm Sci. 2018;124:80-88. doi:10.1016/j.ejps.2018.08.003

56. Chogale MM, Ghodake VN, Patravale VB. Performance parameters and characterizations of nanocrystals: a brief review. Pharmaceutics. 2016;8(3):26. doi:10.3390/pharmaceutics8030026

57. Asiatic acid. Chemical Book Web site. Available from: https://www. chemicalbook.com/ChemicalProductProperty_EN_cb5109340.htm. Accessed October 28, 2021.

58. Bunaciu AA, Udriştioiu EG, Aboul-Enein HY. X-ray diffraction: instrumentation and applications. Crit Rev Anal Chem. 2015;45 (4):289-299. doi:10.1080/10408347.2014.949616

59. Alizadeh MN, Shayanfar A, Jouyban A. Solubilization of drugs using sodium lauryl sulfate: experimental data and modeling. J Mol Liq. 2018;268:410-414. doi:10.1016/j.molliq.2018.07.065

60. Noyes AA, Whitney WR. The rate of solution of solid substances in their own solutions. J Am Chem Soc. 1897;19(12):930-934. doi:10.1021/ja02086a003

61. Abdelghany S, Tekko IA, Vora L, Larrañeta E, Permana AD, Donnelly RF. Nanosuspension-based dissolving microneedle arrays for intradermal delivery of curcumin. Pharmaceutics. 2019;11 (7):308. doi:10.3390/pharmaceutics11070308

62. Kesisoglou F, Panmai S, Wu Y. Nanosizing — oral formulation development and biopharmaceutical evaluation. Adv Drug Deliv Rev. 2007;59(7):631-644. doi:10.1016/j.addr.2007.05.003

63. Lademann J, Richter H, Meinke M, Sterry W, Patzelt A. Which skin model is the most appropriate for the investigation of topically applied substances into the hair follicles? Skin Pharmacol Physiol. 2010;23(1):47-52. doi:10.1159/000257263

64. Gray G, Yardley H. Lipid compositions of cells isolated from pig, human, and rat epidermis. J Lipid Res. 1975;16(6):434-440. doi:10.1016/S0022-2275(20)34493-X

65. Wester RC, Melendres J, Sedik L, Maibach H, Riviere JE. Percutaneous absorption of salicylic acid, theophylline, 2, 4-dimethylamine, diethyl hexyl phthalic acid, and p-aminobenzoic acid in the isolated perfused porcine skin flap compared to man in vivo. Toxicol Appl Pharmacol. 1998;151(1):159-165. doi:10.1006/ taap. 1998.8434

66. Jacobi U, Kaiser M, Toll R, et al. Porcine ear skin: an in vitro model for human skin. Skin Res Technol. 2007;13(1):19-24. doi:10.1111/ j.1600-0846.2006.00179.x

67. Wester RC, Maibach HI. In vivo methods for percutaneous absorption measurements. J Toxicol Cutaneous Ocul Toxicol. 2001;20 (4):411-422. doi:10.1081/CUS-120001866

68. Seto JE, Polat BE, Lopez RF, Blankschtein D, Langer R. Effects of ultrasound and sodium lauryl sulfate on the transdermal delivery of hydrophilic permeants: comparative in vitro studies with full-thickness and split-thickness pig and human skin. $J$ Control Release. 2010;145(1):26-32. doi:10.1016/j.jconrel.2010.03.013

69. Centellian24 madeca cream power boosting formula. DongKook Pharmaceutical Co., Ltd. Available from: http:/www.dkpharm.co. kr/product/view.php?idx=137. Accessed October 28, 2021.

70. Cosmetic Ingredient Review. Safety assessment of Centella asiatica-derived ingredients as used in cosmetics; 2015. Available from: https://www.cir-safety.org/supplementaldoc/safety-assessmentcentella-asiatica-derived-ingredients-used-cosmetics-1. Accessed October 28, 2021. 


\section{Publish your work in this journal}

The International Journal of Nanomedicine is an international, peerreviewed journal focusing on the application of nanotechnology in diagnostics, therapeutics, and drug delivery systems throughout the biomedical field. This journal is indexed on PubMed Central, MedLine, CAS, SciSearch ${ }^{\mathbb{R}}$, Current Contents ${ }^{\mathbb{R}} /$ Clinical Medicine, $^{2}$
Journal Citation Reports/Science Edition, EMBase, Scopus and the Elsevier Bibliographic databases. The manuscript management system is completely online and includes a very quick and fair peer-review system, which is all easy to use. Visit http://www.dovepress.com/ testimonials.php to read real quotes from published authors.

Submit your manuscript here: https://www.dovepress.com/international-journal-of-nanomedicine-journal 